\title{
Theoretical Hydrokinetic Power Potential Assessment of the U-Tapao River Basin Using GIS
}

\author{
Fida Ali ${ }^{1}$, Chatchawin Srisuwan ${ }^{2}$, Kuaanan Techato ${ }^{3, *}$, Adul Bennui ${ }^{4}$, Tanita Suepa ${ }^{5}$ and \\ Damrongrit Niammuad 5
}

1 Department of Sustainable Energy Management, Faculty of Environment Management, Prince of Songkla University, Hat Yai, Songkhla 90110, Thailand; fidaali.akhss@gmail.com

2 Department of Civil Engineering, Faculty of Engineering, Prince of Songkla University, Hat Yai, Songkhla 90110, Thailand; Chatchawin.s@psu.ac.th

3 Environmental Assessment and Technology for Hazardous Waste Management, Faculty of Environmental Management, Prince of Songkla University, Hat Yai, Songkhla 90110, Thailand

4 Southern Regional Center of Geo-Informatics and Space Technology, Faculty of Environmental Management, Prince of Songkla University, Hat Yai, Songkhla 90110, Thailand; adul1445@gmail.com

5 Geo-Informatics and Space Technology Development Agency (GISTDA), Bangkok 10210, Thailand; tanita@gistda.or.th (T.S.); damrongrit@gistda.or.th (D.N.)

* Correspondence: kuaanan.t@psu.ac.th

Received: 17 February 2020; Accepted: 27 March 2020; Published: 6 April 2020

\begin{abstract}
Conventional hydropower technologies such as dams have been criticized due to their negative environmental effects which have necessitated the development of new technologies for sustainable development of hydropower energy. Hydrokinetic (HK) energy is one such emerging renewable energy technology and, in this study, a theoretical potential assessment was done using a Geographic Information System (GIS) and Soil and Water Assessment Tool (SWAT) hydrological model, for the U-Tapao river basin (URB), a major tributary of the Songkhla lake basin (SLB) in southern Thailand. The SWAT was calibrated and validated with SWAT calibration and uncertainty (SWAT-CUP)-SUFI 2 programs using the observed discharge data from the gauging stations within the watershed. The model performance was evaluated based on the Nash-Sutcliffe efficiency (NSE) and the coefficient of determination $\left(R^{2}\right)$ values, achieving 0.62 and 0.60 , respectively, for calibration, and 0.65 and 0.68 for validation which is considered acceptable and can be used to represent flow estimation. The theoretical HK potential was estimated to be $71.9 \mathrm{MW}$ along the $77.18 \mathrm{~km}$ U-Tapao river, which could be developed as a renewable and reliable energy source for the communities living around the river. The method developed could also be applied to river systems around the world for resource and time efficient HK potential assessments.
\end{abstract}

Keywords: riverine hydrokinetic; small hydropower; geographic information system; soil and water assessment tool

\section{Introduction}

Hydropower is the pioneer and most reliable form of renewable energy, currently contributing the highest share of $16 \%$ to the global renewable electricity production [1]. However, in recent years, conventional large hydropower dams have been criticized due to environmental, economic, and social concerns associated with them such as alteration of river ecology, displacement of human settlements, etc. For example, dams built by China and other countries on the Mekong river have significantly altered the river system affecting the livelihood of millions of people living around the river because their agriculture, fishing, and other activities depend on the Mekong river [2]. Such concerns have convinced many countries in the world to enforce environmental protection laws imposing bans on 
further developments of new hydropower dams, such as in the case of Thailand where the development of new hydropower dams is no longer allowed under the country's strict environmental protection laws [3,4]. Situations like these have triggered a search for alternative unconventional means to develop hydropower, while minimizing environmental implications.

Hydrokinetic (HK) energy is one such emerging technology that has the potential to develop hydropower and eliminate the negative environmental effects of conventional technologies. HK energy is the extraction of power from waves, ocean currents, rivers, and streams utilizing the kinetic flow of the water without any dams or river diversions $[5,6]$ which makes it ideal as the majority of unwanted effects of conventional hydropower are the results of river blockades or diversions. Nevertheless, so far, HK is among the least developed renewable energy technologies in the world, with the majority of turbine designs either in development, prototype, or limited test-bed stages $[7,8]$. However, being environmentally friendly, HK technology has attracted the interests of both individual researchers and governments alike with a gradual increase in the research especially with respect to the potential assessments of riverine hydrokinetic energy.

GIS-based HK potential assessments of the rivers and streams in the USA have estimated a total theoretical potential of $1381 \mathrm{TWh} / \mathrm{yr}$, whereas the technically recoverable HK power is $120 \mathrm{TWh} / \mathrm{yr}$ which fulfills $3 \%$ of the country's annual electricity demand [9]. A similar potential assessment of Canadian in-land waterways revealed a theoretical power generation capacity of 710,000 MW with $97.5 \%$ confidence of $433,000 \mathrm{MW}$ recoverable potential [10]. The assessment of the Neris river in Lithuania using GIS for wet, normal, and dry sessions showed a mean annual power density of $0.38 \mathrm{~kW} / \mathrm{m}^{2}, 0.24 \mathrm{~kW} / \mathrm{m}^{2}$, and $0.14 \mathrm{~kW} / \mathrm{m}^{2}$ respectively, while the power capacity over a $100 \mathrm{~m}$ river segment investigated was $0.124,0.052$, and $0.024 \mathrm{MW}$ for the same three periods [11]. In another study, $2000 \mathrm{~km}$ of the small Lithuanian rivers and streams were investigated for their potential HK energy. The average HK for $1 \mathrm{~km}$ of river segment in south-eastern Lithuania was $0.0453 \mathrm{MW}$, whereas the western and central parts were $0.0408 \mathrm{MW}$ and $0.0382 \mathrm{MW}$ [12]. Several GIS-based HK potential assessments were also carried out in different river basins of Nigeria. The Soil and Water Assessment Tool (SWAT) based theoretical HK potential of the Oshe and Konsun rivers in the area upstream of the Ikre George dam in Nigeria yielded 9.542 MW for Oshe and 1.161 MW for the Konsun river basin [13]. The HK energy potential of three river basins of Kwara state in Nigeria was done by [14] where the potentials of the Asa, Oyun, and Awun rivers were estimated to be $41.63 \mathrm{MW}, 98.39 \mathrm{MW}$, and 154.82 MW respectively. As evident by the studies above, the use of GIS and SWAT is an effective and reliable source for HK energy potential assessment.

As a result, the aim of this study is the theoretical HK potential assessment using the GIS and SWAT model of the U-Tapao river basin (URB), which is a major tributary of the Songkhla Lake basin (SLB) in the southern region of Thailand. To the best of our knowledge, this is the first HK potential assessment of any river system in Thailand, and it is the first study to employ the SWAT model for HK assessment of rivers in the tropical regions of Southeast Asia. Given the fact that a ban has been imposed on further development of hydropower dams in Thailand, HK technology could be a vital source of developing hydropower. With its ability to operate in relatively small rivers and stream, it is an ideal platform for the rural electrification of communities living and farming around rivers with minimal impact on the river ecology and surrounding environments. The method developed in this study could also be applied to rivers around the world for a time- and resource-effective assessment of theoretical HK potential.

\section{Materials and Methods}

\subsection{Study Area}

The U-Tapao river basin (URB) is situated within the SLB in Southern Thailand between longitude $100^{\circ} 10^{\prime}$ through $100^{\circ} 37^{\prime} \mathrm{E}$ and latitude $6^{\circ} 28^{\prime}$ through $7^{\circ} 10^{\prime} \mathrm{N}$ and is the major tributary, as shown in Figure 1. The U-Tapao river is $77 \mathrm{~km}$ long and $40 \mathrm{~km}$ wide covering an area of $2305 \mathrm{~km}^{2}$. The climate 
of the URB is tropical and has two monsoon seasons, namely the southwest monsoon with rainfall between May to September and the northeast monsoon with a rainfall period from October to January. With two monsoons seasons, the wet period in the URB starts from May and continues to January. The average rainfall between July and February per annum is $1474.10 \mathrm{~mm}$, while the dry season (March to June) receives about $389.90 \mathrm{~mm}$ of rainfall. The temperature fluctuates between $27.17{ }^{\circ} \mathrm{C}$ and $28.46{ }^{\circ} \mathrm{C}$, all year round [15].

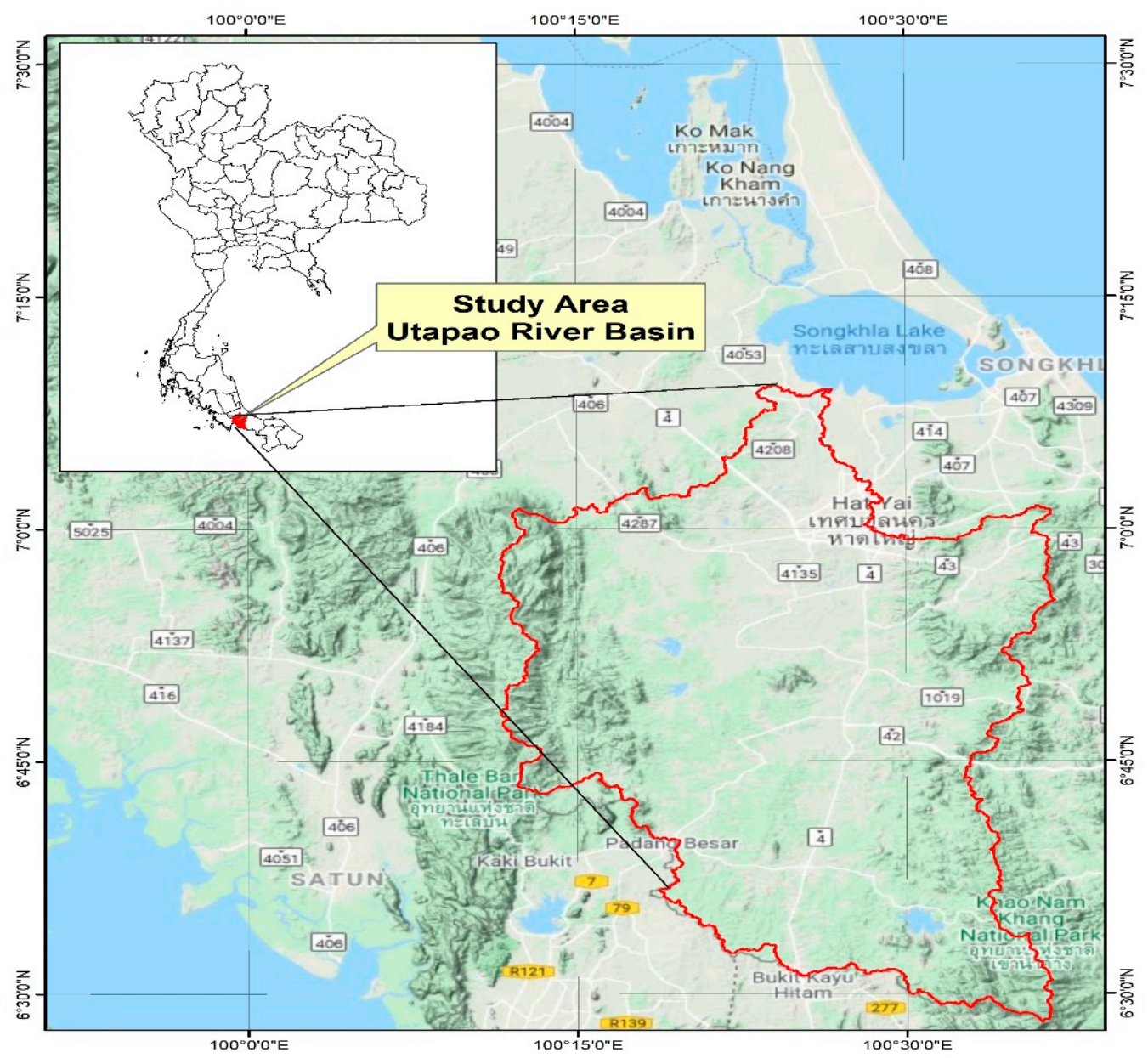

Figure 1. The study area.

\subsection{Theoretical Hydrokinetic Potential Modeling}

The in-stream or riverine theoretical hydrokinetic power $P_{t h}$ in a river segment is calculated as Equation (1) $[9,10]$ :

$$
P_{t h}=\gamma \times Q \times \Delta H
$$

where $P_{t h}$ is the theoretical hydrokinetic power in watts, $\gamma$ is the specific weight of water $\left(9800 \mathrm{~N} / \mathrm{m}^{3}\right)$, $\mathrm{Q}$ is the flow rate of the stream $\left(\mathrm{m}^{3} / \mathrm{s}\right)$, and $\Delta H$ is the change in hydraulic head between the beginning and end of the river segment.

As evident by Equation (1), the hydraulic head and stream flow rates are the two most important variables for theoretical HK power calculation in a river segment. In this research, ArcGIS was used for the calculation of hydraulic head and the ArcSWAT hydrological model was used for the simulation of flow. The overview of the methodology is shown in Figure 2. 


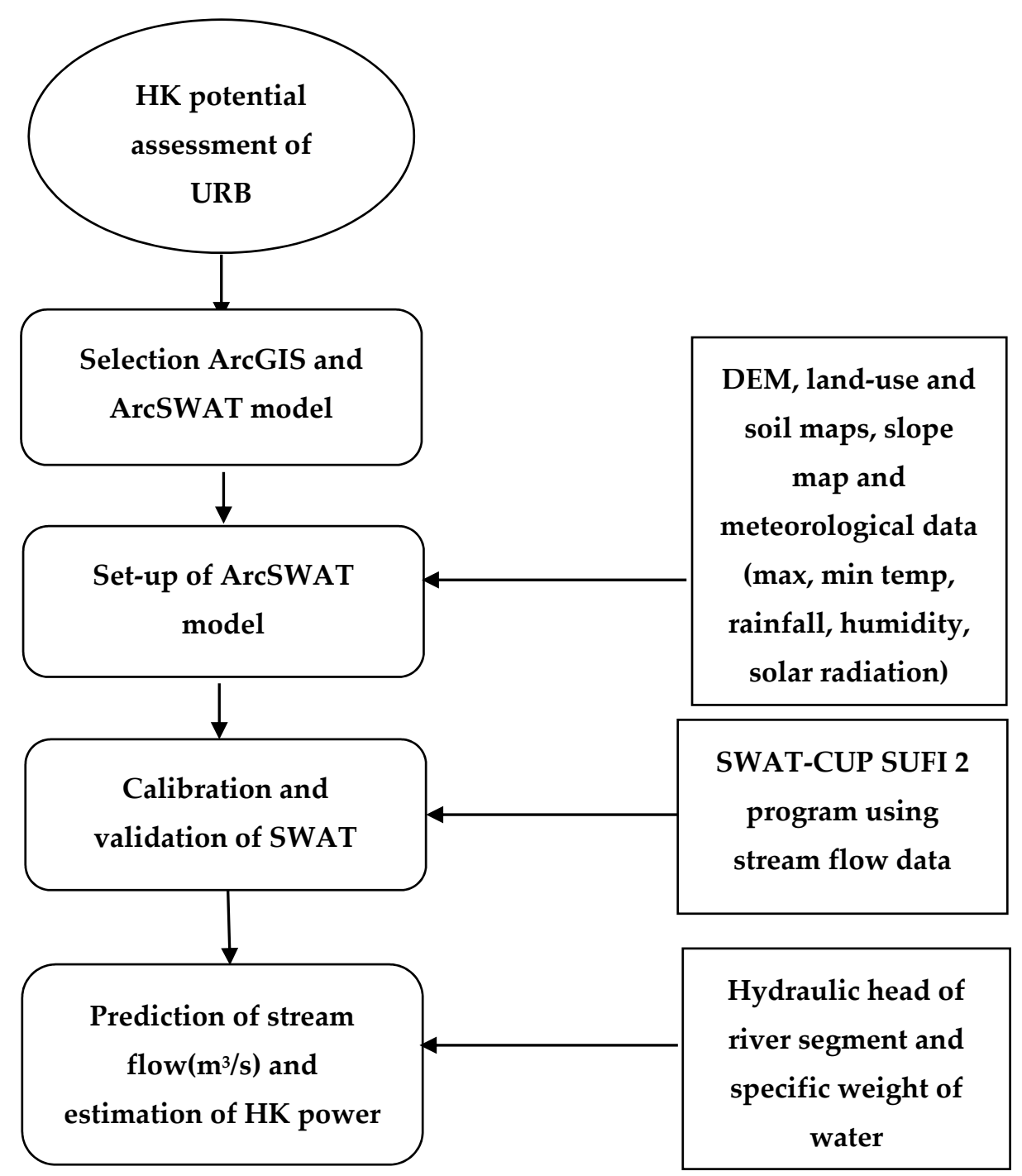

Figure 2. Overview of the adopted methodology.

\subsection{Description of the SWAT Model}

The SWAT is a hydrological model developed by the U.S. Department of Agricultural Research Services to assess the effects of land management practices on water, sediment, and agricultural chemical yields in ungauged, large watersheds over long periods of time [16]. The hydrologic cycle in the SWAT is simulated based on the water balance Equation (2) as follows:

$$
\mathrm{SW}_{\mathrm{t}}=\mathrm{SW}_{\mathrm{o}}+\sum_{\mathrm{i}=1}^{\mathrm{t}}\left(\mathrm{R}_{\text {day }}-\mathrm{Q}_{\text {surf }}-\mathrm{E}_{\mathrm{a}}-\mathrm{W}_{\text {seep }}-\mathrm{Q}_{\mathrm{gw}}\right)
$$

where $\mathrm{SW}_{\mathbf{t}}$ is the final soil content $(\mathrm{mm}), \mathrm{SW}_{\mathrm{o}}$ is the initial water content $(\mathrm{mm}), \mathrm{R}_{\text {day }}$ is the rainfall $(\mathrm{mm}), Q_{\text {surf }}$ is the surface runoff $(\mathrm{mm}), \mathrm{E}_{\mathrm{a}}$ is the amount of evapotranspiration $(\mathrm{mm}), \mathrm{w}_{\text {seep }}$ is the water amount entering the vadose zone from the soil, and $\mathrm{Q}_{\mathrm{gw}}$ is the amount of return flow.

The SWAT model delineates the watershed into sub-basins and hydrological response units (HRUs) using the digital elevation model (DEM). During the delineation of the watershed, the streams networks are also defined by the SWAT. The HRUs are portions of sub-basins that possess unique land management and soil attributes. The HRU is an area within the sub-basin with a particular land use, management, and soil which helps to simplify the running of the model as they lump together areas with similar land use, management, and soil. This adds more accuracy for the predication hydrological cycle in the sub-basin and ultimately the whole watershed. The SWAT model simulates the runoff 
(streamflow rate) in the watershed and channels using the DEM, soil map, land-use map, meteorological data (temperature, rainfall, solar radiation, wind speed, and humidity), and the streamflow data from gauging stations for calibration and validation of the model [14,16]. ArcSWAT2012, which is a graphical user interface program that links the SWAT hydrologic model and ArcGIS10.5, was used for the simulation of flow discharge in this study. The SWAT model can reliably predict the streamflow in a watershed for a longer period giving a good idea of year-round flow rates of streams or rivers for extended periods which is essential for the calculation of hydropower. This reliability of the SWAT model has resulted in its application in watershed management, agricultural and hydropower applications throughout the world [17-19]. The SWAT model makes the simulation of flow quicker and reliable in a watershed [20].

\subsection{Input Data for the SWAT Model}

As discussed, the SWAT model utilizes different datasets ranging from soil, meteorological, and streamflow for the simulation of flow rate in a watershed, the dataset used for this study are described in the following sections.

\subsubsection{DEM}

The topography of a place is defined by a DEM that describes the elevation of any point in each area at a specific spatial resolution. A $30 \mathrm{~m}$ DEM obtained from the Royal Thai Survey Department (RTSD) was used for this study, as shown in Figure 3. The DEM is used by the SWAT model to delineate the watershed into small sub-basins, HRUs, and for the definition of the stream network tracing the rivers and streams throughout the watershed.

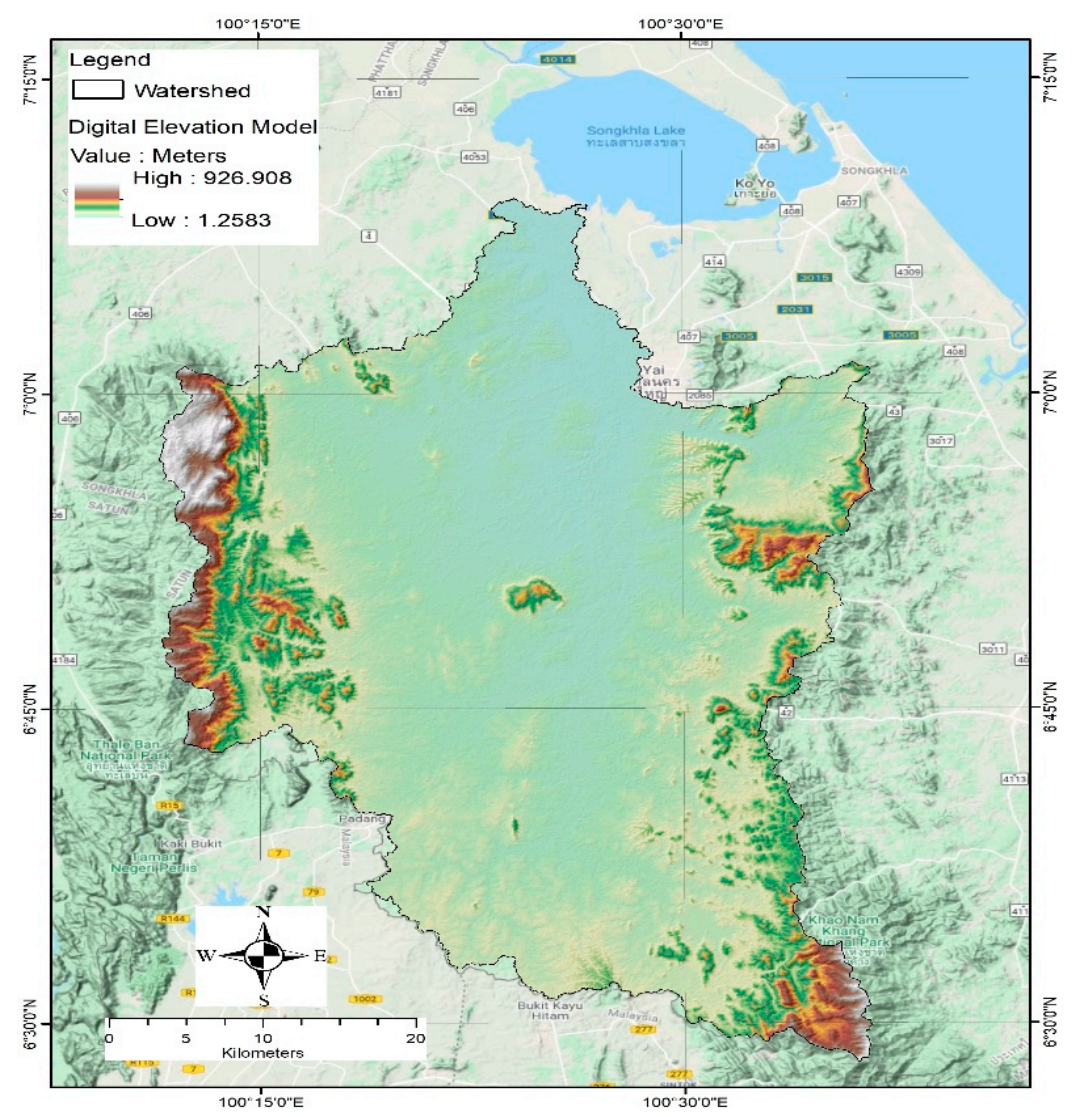

Figure 3. Digital elevation model (DEM) of the U-Tapao river basin. 


\subsubsection{Land-Use Map}

The land-use map shows the type and extent of land management carried out in a watershed which ultimately affects the flow of water through the watershed. A land-use map of the URB from the Land Development Department of Thailand was used, as shown in Figure 4. Agriculture is the dominant land use in the watershed with almost $73 \%$ of the land utilized for it, while range-grass accounts for the smallest land use with only $0.038 \%$.

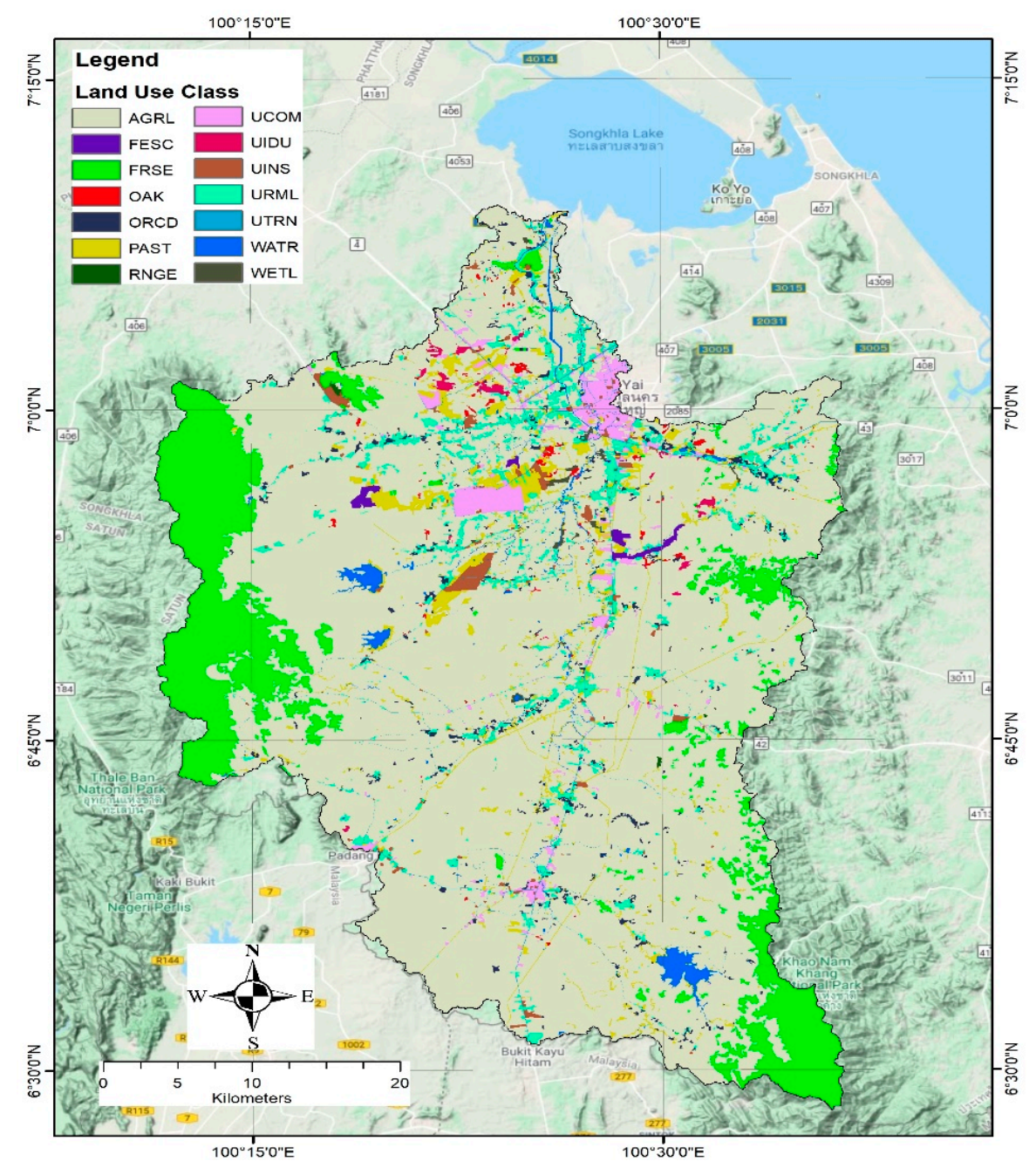

Figure 4. The land-use map of the U-Tapao river basin (URB) (use color).

\subsubsection{Soil Map}

The soil map shows the type and properties of soil in the watershed which is very important as the water flow in the watershed depends on the type of soil it is passing through. The SWAT requires different physical, chemical, and texture properties of soil such as soil texture, available water content, hydraulic conductivity, bulk density, and organic carbon content of different layers for each soil type. The soil map from the Land Development Department of Thailand was used, as shown in Figure 5. There are 41 different types of soil present in the URB with slope-complex soil accounting for most of the area, i.e., $27 \%$, whereas swamp soil accounts for only $0.01 \%$ of the watershed. 


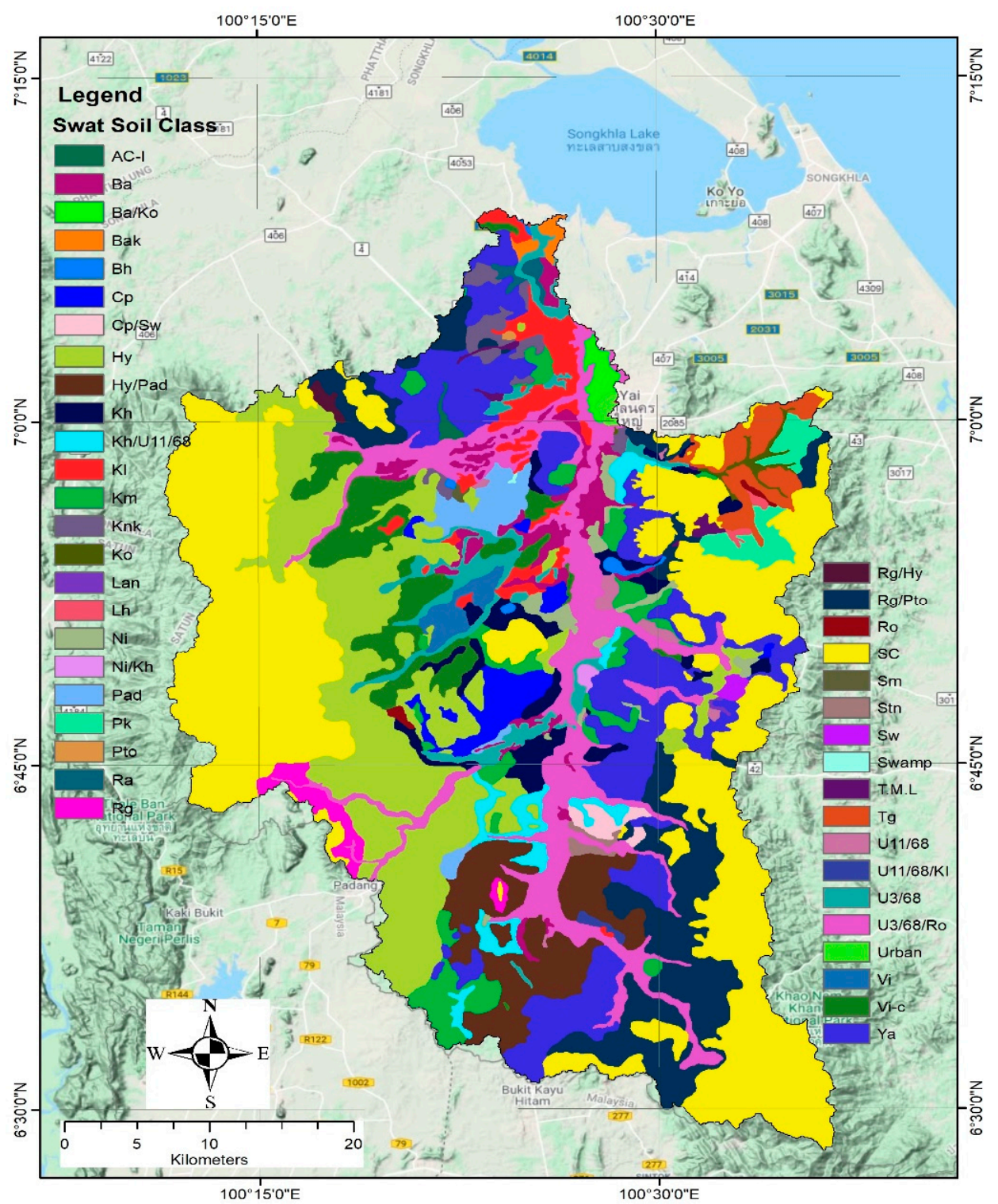

Figure 5. Soil map of the URB (use color).

\subsubsection{Meteorological and River Flow Data}

The SWAT requires daily meteorological data of maximum and minimum temperature, rainfall, solar radiation, wind speed, and relative humidity for the simulation of water flow in the watershed. For this study, 11 years of the meteorological data were obtained from the Royal Meteorological Department of Thailand for two weather stations, namely Sa Dao and Kho Hong, located within the URB.

The SWAT requires a specific format for the meteorological data called WGEN user. To arrange the data in the WGEN user format, an online Excel-based macro file named WGNmaker4 [21] was used. WGNmaker4 calculates and arranges the weather station data in the WGEN user format as required by the SWAT.

The SWAT also requires the streamflow data for the calibration and validation of the model. For this study, 11 years of flow data from 2000 to 2010 were obtained from the Royal Thai Irrigation Department for the stream gauging stations within the URB. 


\subsection{Calibration, Validation, and Sensitivity Analysis of the SWAT Model}

Calibration of a hydrological model is the adjustment of various parameters that affects the flow of water in the watershed in order to minimize the difference of the model output and the discharge data of the gauging stations. The goal of calibration is to enable the SWAT model to simulate and predict the flow in the watershed as close as possible to the observed data obtained from the gauging stations. This study used SWAT-CUP, which is a freely available computer-based program for the calibration, validation, and sensitivity analysis of the SWAT model. The SWAT-CUP program links SUFI 2, PSO, GLUE, ParaSol, and MCMC procedures to the SWAT [22]. The semi-automated sequential uncertainty fitting (SUFI2) method was used for this study. SUFI 2 is an iterative method which narrows down the range of parameters after each iteration reaches the desired output range [23]. Once the model is calibrated it is validated again without changing the parameters adjusted in the calibration stage.

Sensitivity analysis is finding out and adjusting the parameters which most affect the flow simulation. The sensitivity analysis helps the model rapidly attain the desired results, as only the relevant parameters are adjusted which otherwise would take a much longer time if all parameters were adjusted. The SUFI 2 uses two methods, namely global and local sensitivity analysis. For this study, mainly the global sensitivity analysis was adopted.

The performance of the model was tested using the statistical criteria of the Nash-Sutcliffe efficiency (NSE) and the coefficient of determination $\left(R^{2}\right)$, along with visual comparison $[24,25]$. The Nash-Sutcliffe coefficient measures model efficiency by relating the goodness-of-fit of the model to the difference of the measured data and is calculated by Equation (3) as follows:

$$
E_{N s}=1-\frac{\sum_{i=1}^{n}\left(q_{s}-q_{s i}\right)^{2}}{\sum_{i=1}^{n}\left(q_{o i}-q_{0}\right)^{2}}
$$

where ENS is the Nash-Sutcliffe coefficient, $\mathrm{q}_{\mathrm{si}}$ is the simulated flow, $\mathrm{q}_{\mathrm{oi}}$ is the observed flow, $\mathrm{q}_{\mathrm{o}}$ is an average of observed flow, and $\mathrm{n}$ is the number of months.

The coefficient of determination $\left(R^{2}\right)$ represents the relationship between the observed values and the simulated values from the model and is calculated by Equation (4) as follows:

$$
R^{2}=\frac{\left[\sum_{i=1}^{n}\left(q_{s i}-q_{s}^{-}\right)\left(q_{o i}-q_{o}^{-}\right)\right]^{2}}{\sum_{i=1}^{n}\left(q_{s i}-q_{s}^{-}\right)^{2} \sum_{i=1}^{n}\left(q_{o i}-q_{o}^{-}\right)^{2}}
$$

where $\mathrm{q}_{\mathrm{si}}$ is the simulated flow, $\mathrm{q}_{\mathrm{oi}}$ is the observed flow, and $\mathrm{q}_{\mathrm{o}}$ is the average of observed flow.

\section{Results and Discussion}

\subsection{Delineation of Watershed into Sub-Basins and HRUs}

The SWAT model delineates the watershed into sub-basins based on the stream network using the of the watershed. The sub-basins are further delineated into HRUs using the soil and land-use map. The HRUs are basically small areas within the sub-basin with homogenous land use or soil type. ArcSWAT delineated the URB into 38 sub-basin and 295 HRUs. Figure 6 shows the stream network, sub-basins of the URB. 


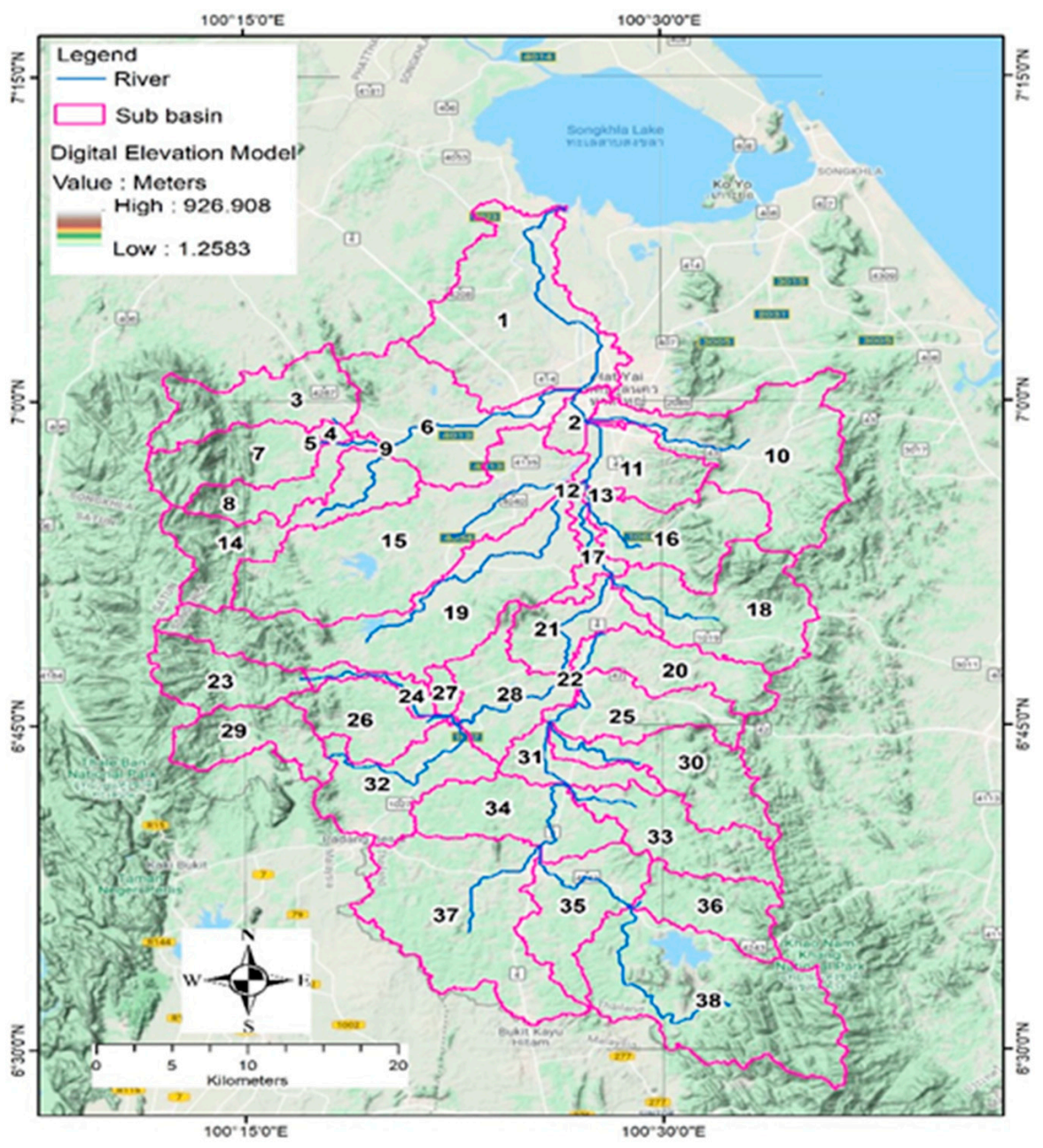

Figure 6. Sub-basins and stream network of the U-Tapao river basin (use color).

\subsection{Calibration, Validation, Sensitivity, and Uncertainty Performance of the Model}

The SWAT model was calibrated using SWAT-CUP SUFI 2 from 2000 to 2005 with the first two years as the warm-up period, as shown in Figure 7, and validated from 2006 to 2010 using the monthly flow rates.

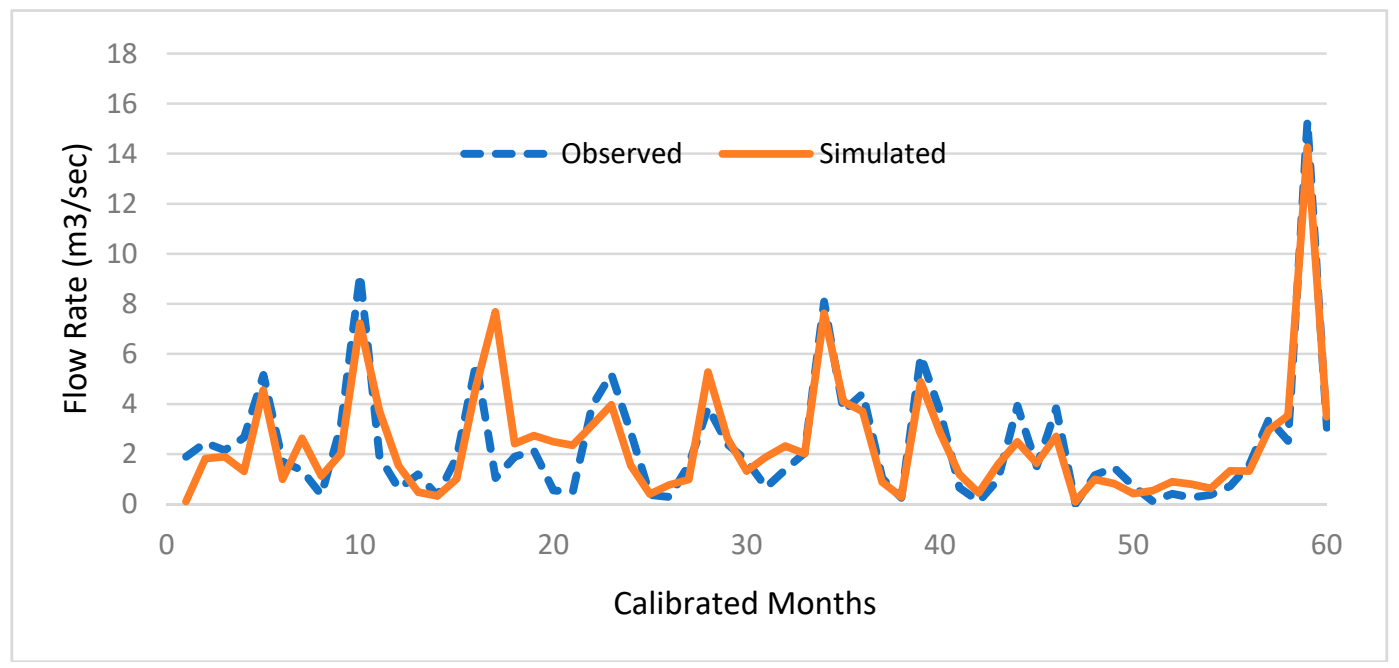

Figure 7. Calibration of the Soil and Water Assessment Tool (SWAT) model (use color). 
The global sensitivity analysis of the SWAT-CUP identified SLSUBBSN (average slope length), OV_N (Manning's " $n$ " value for overland flow), REVAP (groundwater evaporation coefficient), ESCO (soil evaporation compensation factor), and CH_K2 (effective channel hydraulic conductivity) as the most sensitive parameters for the calibration of flow discharge. The results showed a good correlation between the observed flow and the simulated flow, as the model achieved NSE and $\mathrm{R}^{2}$ values of 0.62 and 0.60 for the calibration period, and NSE and $R^{2}$ of 0.6 and 0.68 , respectively, for the validation period which is considered acceptable [26], and thus they can be used to represent the flow for the hydrokinetic energy estimations. The p-factor (percentage of measured data bracketed by the $95 \%$ prediction boundary) and the r-factor which is the average width of the 95PPU (percent prediction uncertainty) band divided by the standard deviation of the measured variable were used for the uncertainty analysis associated with flow predictions used for the uncertainty analysis of SWAT estimation. The value of both $\mathrm{p}$-factor and $\mathrm{r}$-factor ranged between 0 and 1 , with a p-factor close to 1 indicating very high model performance.

The calibration result indicates that some observed peak flows during 2003 and 2005 did not fall under the 95PPU band, which happened because the SWAT was unable to simulate the extreme events resulting in an underprediction of some large flows in the URB. The values of 0.60 and 0.74 were achieved for $\mathrm{p}$-factor and r-factor, respectively, for calibration, while 0.68 and 0.70 were achieved for the validation period, which were well within the acceptable ranges [27]. Some of the meteorological data such as solar radiation and wind speed obtained from the stations were missing which were filled using satellite-based climate data. The certainty would have been improved further with the availability of good input data.

\subsection{Calculation of Mean Annual Flow Rate of Streams and Hydraulic Head}

The average monthly flows for the years from 2002 to 2010 were simulated using the SWAT model and used to calculate the mean annual flow rate of all 38 sub-basins of the URB. The result showed that Sub-basin 1 had the highest flow rate of $66.7 \mathrm{~m}^{3} / \mathrm{s}$, while Sub-basin 20 accounted for the lowest flow rate of $1.4 \mathrm{~m}^{3} / \mathrm{s}$.

The elevation difference between the starting point and the end of the river segment was calculated using the DEM to estimate the hydraulic head of the river segment associated with each sub-basin. The highest hydraulic head was recorded in Sub-basin 3 with $561.75 \mathrm{~m}$ due to its high slope terrain, whereas the nearly flat topography of Sub-basin 12 had the lowest hydraulic head with only $0.93 \mathrm{~m}$. The mean annual flow rates and hydraulic heads were used to estimate the theoretical hydrokinetic potential of the URB.

\subsection{Estimation of Theoretical Hydrokinetic Power Potential}

The theoretical HK energy potential of the URB was calculated using Equation (1). The HK potential was calculated individually for river segments associated with each sub-basin based on their mean annual water flow and hydraulic head, as shown in Figure 8. Sub-basin 11 had the highest theoretical HK potential with 11.9 MW and Sub-basin 5 had the lowest HK potential with $30 \mathrm{~kW}$. Finally, the theoretical potentials of all river segments were added up to calculate the overall theoretical HK potential of the URB. The total theoretical HK potential of the $77 \mathrm{~km}$ long URB was estimated as 71.9 MW. 


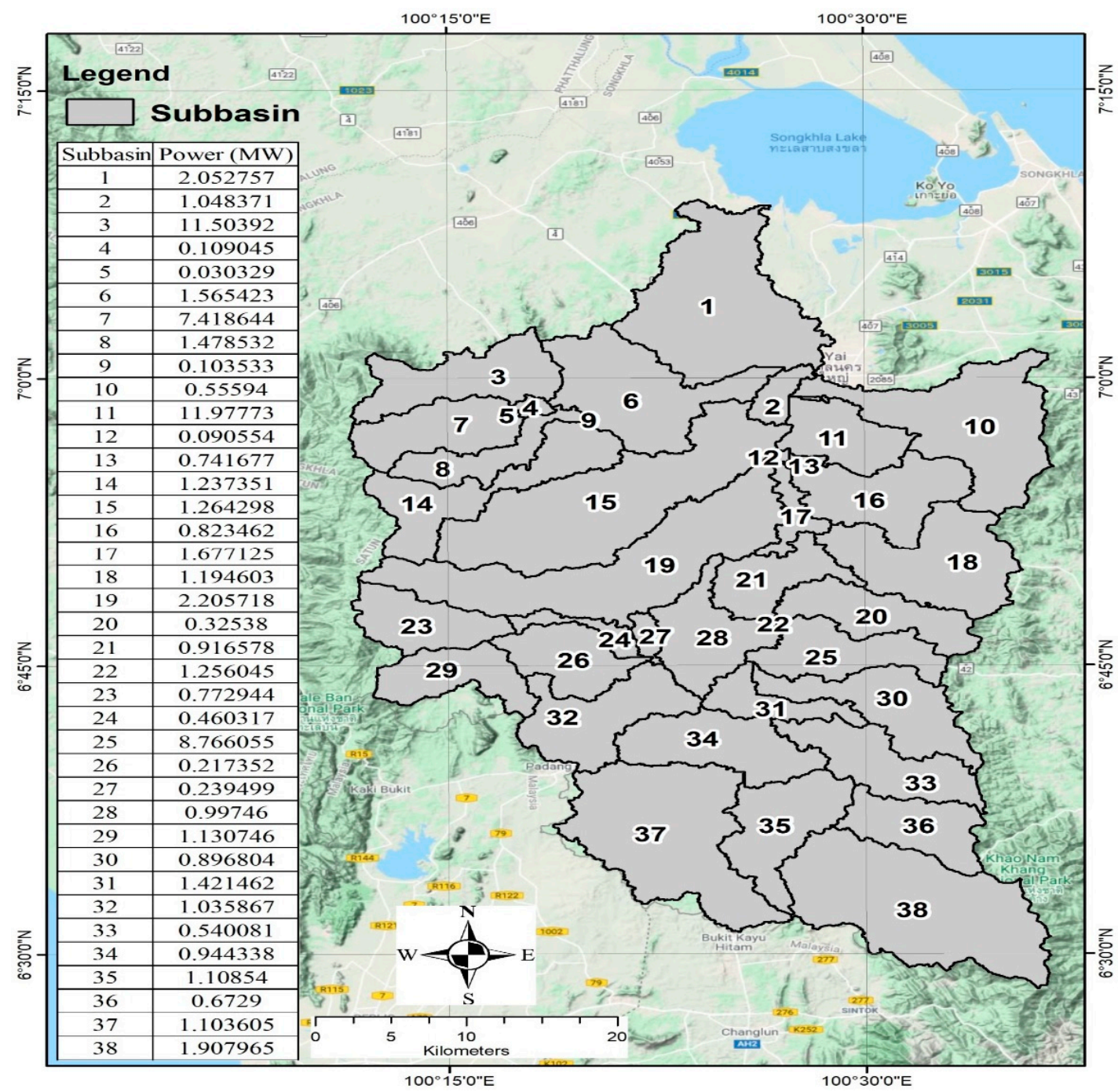

Figure 8. Theoretical hydrokinetic power potential of the URB.

\section{Conclusions}

HK energy is an emerging renewable energy technology that has the potential to develop hydropower sustainably, avoiding the negative impacts of conventional methods. Although HK is still in its early phase of development, governments and researchers have already started working on the possibilities of deploying this technology for the sustainable future of hydropower. The assessment of available potential in the rivers and streams is an essential part of the development of riverine HK energy and the advent of satellite technologies along with remote sensing software such as GIS has made this task more time- and resource-efficient. In this study, a GIS-based technique to assess the theoretical HK potential was developed using the SWAT hydrological model to simulate the flow discharge of the URB in SLB southern Thailand. The SWAT model with its ability to simulate the water flow reliably is gaining popularity especially in the assessments of hydropower potential around the world. The theoretical HK potential of the $77 \mathrm{~km}$ long U-Tapao river was estimated as $71.9 \mathrm{MW}$. Although the theoretical HK potential assessment was the preliminary task, it provided valuable information about the available HK power in a river system. Using the results of this assessment, a more detailed technical assessment could be carried out in the future specifically targeting the river segments offering higher potentials. This could help pinpoint the areas with the greater potential, saving time and resources. For the technical assessment, the type and efficiency of the HK turbines would be selected based on the site specifications. 
HK technology has enormous potential for the development of energy infrastructure in relatively undeveloped rural areas due to its low initial cost, less demanding and relatively simple construction, along with easy maintenance requirements. This theoretical potential assessment of the URB provides reliable data for the government and other potential developers for the development of HK energy in southern Thailand which is experiencing a rapid increase in energy demand due to activities such as tourism and services industries. In addition to the URB, the method developed in this study is equally effective for the assessment of riverine HK energy of river systems not only in Thailand but around the globe.

Author Contributions: Conceptualization, F.A.; data curation, F.A., A.B., T.S., and D.N.; software, F.A. and A.B.; writing —original draft preparation, F.A.; writing — review and editing, C.S. and K.T.; supervision, C.S. and K.T. All authors have read and agreed to the published version of the manuscript.

Funding: This research was funded by Prince of Songkla University (PSU) Hat Yai, Songkhla 90110, Thailand, under a grant of the "Thailand Education Hub Scholarship for ASEAN (TEH-AC), grant number 047/2018" and the "Interdisciplinary Graduate School of Energy System (IGS-Energy) grant number 1-2018/112".

Conflicts of Interest: The authors declare no conflict of interest.

\section{References}

1. Hydropower Status Report. IHA Central Office IHA Regional and National Offices, 2018. Available online: https://www.hydropower.org/sites/default/files/publications-docs/iha_2018_hydropower_status_ report_4.pdf (accessed on 12 January 2020).

2. Intralawan, A.; Wood, D.; Frankel, R.; Fah, M. Economic, Environmental and Social Impacts of Hydropower Development in the Lower Mekong Basin. 2016. Available online: http://www.mfu.ac.th/nremc/ (accessed on 21 June 2019).

3. International Renewable Energy Agency. Thailand Renewable Energy Outlook Based on Renewables Readiness Assessment and REmap Analysis. 2017. Available online: https://www.irena.org/-/media/Files/ IRENA/Agency/Publication/2017/Nov/IRENA_Outlook_Thailand_2017.pdf (accessed on 8 June 2019).

4. Supriyasilp, T.; Pongput, K.; Robkob, C. Small Hydropower Development and Legal Limitations in Thailand. In Proceedings of the World Renewable Energy Congress-Sweden, Linköping, Sweden, 8-13 May 2011; Volume 57, pp. 2682-2689. [CrossRef]

5. Kosnik, L.-R.D. The Potential of Water Power in the Fight Against Global Warming. SSRN Electron. J. 2008, 36, 3252-3265. [CrossRef]

6. Dixon, D. EPRI Project Manager Assessment of Waterpower Potential and Development Needs. 2007. Available online: www.epri.com (accessed on 25 January 2020).

7. Zhou, D.; Deng, Z.D. Ultra-low-head hydroelectric technology: A review. Renew. Sustain. Energy Rev. 2017, 78, 23-30. [CrossRef]

8. Khan, M.J.; Iqbal, M.T.; Quaicoe, J.E. River current energy conversion systems: Progress, prospects and challenges. Renew. Sustain. Energy Rev. 2008, 12, 2177-2193. [CrossRef]

9. Jacobson, P. EPRI Project Assessment and Mapping of the Riverine Hydrokinetic Energy Resource in the Continental United States. 2012. Available online: www.epri.com (accessed on 25 January 2020).

10. Bomhof, J. Estimating Flow, Hydraulic Geometry, and Hydrokinetic Power at Ungauged Locations in Canada; Ottawa-Carleton Institute of Civil Engineering, University of Ottawa: Ottawa, ON, Canada, 2014.

11. Punys, P.; Adamonyte, I.; Kvaraciejus, A.; Martinaitis, E.; Vyciene, G.; Kasiulis, E. Riverine hydrokinetic resource assessment. A case study of a lowland river in Lithuania. Renew. Sustain. Energy Rev. 2015, 50, 643-652. [CrossRef]

12. Jakimavičius, D.; Gailiušis, B.; Šarauskiene, D.; Jurgelenaite, A.; Meilutyte-Lukauskiene, D. Assessment of the riverine hydrokinetic energy resources in Lithuania. Baltica 2014, 27, 141-150. [CrossRef]

13. Salau, W.; Ifabiyi, P.I. Hydro-geomorphic factors and the potential of hydrokinetic power production upstream of ikere gorge dam, Nigeria. Geosfera Indonesia 2019, 4, 25-43. [CrossRef]

14. Adeogun, A.G.; Ganiyu, H.O.; Ladokun, L.L.; Ibitoye, B.A. Evaluation of hydrokinetic energy potentials of selected rivers in Kwara State, Nigeria. Environ. Eng. Res. 2019, 25, 267-273. [CrossRef] 
15. Patsinghasanee, S.; Jarusdumrongnit, B.; Chitprom, P.; Chub-uppakarn, T. Flood Forecast System in Songkhla Lake River Basin by Department of Water Resources. In Proceedings of the 5th PSU-UNS International Conference on Engineering and Technology (ICET-2011), Phuket, Thailand, 2-3 May 2011. Available online: http://phoenix.eng.psu.ac.th/pec9/icet/paper/ce/P45.pdf (accessed on 14 October 2019).

16. Neitsch, S.L.; Arnold, J.G.; Kiniry, J.R.; Williams, J.R. College of Agriculture and Life Sciences Soil and Water Assessment Tool Theoretical Documentation Version 2009. 2011. Available online: https://swat.tamu.edu/ media/99192/swat2009-theory.pdf (accessed on 9 June 2019).

17. Papatheodoulou, A.; Tzoraki, O.; Panagos, P.; Taylor, H.; Ebdon, J.; Papageorgiou, G.; Pissarides, N.; Antoniou, K.; Christofi, G.; Dorlfinger, G.; et al. Simulation of daily discharge using the distributed model SWAT as a catchment management tool: Limnatis River case study. In Proceedings of the First International Conference on Remote Sensing and Geoinformation of Environment, Paphos, Cyprus, 5 August 2013; p. 87951M. [CrossRef]

18. Hallouz, F.; Meddi, M.; Mahé, G.; Alirahmani, S.; Keddar, A. Modeling of discharge and sediment transport through the SWAT model in the basin of Harraza (Northwest of Algeria). Water Sci. 2018, 32, 79-88. [CrossRef]

19. Kusre, B.C.; Baruah, D.C.; Bordoloi, P.K.; Patra, S.C. Assessment of hydropower potential using GIS and hydrological modeling technique in Kopili River basin in Assam (India). Appl. Energy 2010, 87, $298-309$. [CrossRef]

20. Mehan, S.; Neupane, R.P.; Kumar, S. Coupling of SUFI 2 and SWAT for Improving the Simulation of Streamflow in an Agricultural Watershed of South Dakota. Hydrol. Curr. Res. 2017, 8. [CrossRef]

21. Texas A\&M University. WGENmaker4. 2010. Available online: http://swatmodel.tamu.edu/software/linksto-related-software (accessed on 30 October 2019).

22. Abbaspour, K.C. SWAT-CUP SWATCalibration and Uncertainty Programs; Swiss Federal Institute of Aquatic Science and Technology: Dübendorf, Switzerland, 2015.

23. Khalid, K.; Ali, M.F.; Rahman, N.F.A.; Mispan, M.R.; Haron, S.H.; Othman, Z.; Bachok, M.F. Sensitivity Analysis in Watershed Model Using SUFI-2 Algorithm. Procedia Eng. 2016, 162, 441-447. [CrossRef]

24. Roth, V.; Nigussie, T.K.; Lemann, T. Model parameter transfer for streamflow and sediment loss prediction with SWAT in a tropical watershed. Environ. Earth Sci. 2016, 75, 1321. [CrossRef]

25. Yang, Y.; Wang, G.; Wang, L.; Yu, J.; Xu, Z. Evaluation of Gridded Precipitation Data for Driving SWAT Model in Area Upstream of Three Gorges Reservoir. PLoS ONE 2014, 9, e112725. [CrossRef] [PubMed]

26. Ayele, G.; Teshale, E.; Yu, B.; Rutherfurd, I.; Jeong, J.; Ayele, G.T.; Teshale, E.Z.; Yu, B.; Rutherfurd, I.D.; Jeong, J. Streamflow and Sediment Yield Prediction for Watershed Prioritization in the Upper Blue Nile River Basin, Ethiopia. Water 2017, 9, 782. [CrossRef]

27. Narsimlu, B.; Gosain, A.K.; Chahar, B.R.; Singh, S.K.; Srivastava, P.K. SWAT Model Calibration and Uncertainty Analysis for Streamflow Prediction in the Kunwari River Basin, India, Using Sequential Uncertainty Fitting. Environ. Process. 2015, 2, 79-95. [CrossRef]

(C) 2020 by the authors. Licensee MDPI, Basel, Switzerland. This article is an open access article distributed under the terms and conditions of the Creative Commons Attribution (CC BY) license (http://creativecommons.org/licenses/by/4.0/). 